\title{
DISASTER INFORMATION PROVISION FOR INTERNATIONAL TOURISTS USING AN INTERPRETER APPLICATION
}

\author{
TAKEYASU SUZUKI \\ Disaster and Environmentally Sustainable Administration Research Center, University of Yamanashi, Japan
}

\begin{abstract}
With its new tourism-focus, Japan has been encouraging an increase in foreign tourists; consequently, over the past eight years, foreign tourist numbers have slowly been growing toward the 2020 target of 40 million. However, as Japan is a natural disaster-prone country, foreign tourists are often present when natural disasters occur, at which times they attempt to find information on the internet, often without success. It has been reported that while most foreign tourists seek information from the staff at their accommodation, many small-to-medium-sized tourist facilities in Japan have few employees who can speak foreign languages. Translation AI applications are now being widely used by travelers, with the author having been involved in a collaboration with several companies to develop a sophisticated interpreter application for smartphones that can handle one-to-many and multilingual translations. Therefore, based on the Tourism Crisis Management Plan, this study examined the use of this application to provide information to foreign tourists during a simulated disaster at an amusement park. The simulation was found to be extremely effective, and revealed that foreign tourist disaster information needed to account for the international differences in legal systems, disaster experiences, natural predispositions, lifestyles and cultures, and needed to provide plain language information on: (1) what was happening, (2) the disaster progression, and (3) the actions to be taken.

Keywords: disaster response simulation, foreign tourists, interpretation app, tourism crisis management, amusement park.
\end{abstract}

\section{INTRODUCTION}

As Japan is a natural disaster-prone country, foreign tourists have often been present at times of natural disaster, at which times they have attempted to find information on the internet often without success. It has been reported that while most foreign tourists seek information from the staff at their accommodation, many small-to-medium-sized tourist facilities in Japan have few employees who can speak foreign languages.

The development of AI technology means that it is now possible to provide information in many languages using megaphone-type translators, small voice-based translators, or smartphone translation apps that enable two-way conversations. As these types of translators are also being used in disaster management drills in many municipalities and prefectures in Japan, they could also be effective for small- and medium-sized tourist facilities during disasters. However, these translators can only translate one language at a time and when using the applications, the two people need to be talking face to face. Therefore, as it was not possible for tourist facilities to talk to tourists in multiple languages, the author began working with several companies to develop an interpreter app that enabled one-to-many, Japanese-to-multilingual conversations, and began research on the use of this app for international tourists during disasters in Japan.

Disaster information needs to be in plain language and needs to tell people: (1) what is happening, (2) what progress is being made, and (3) the actions they need to take. Therefore, to assess the viability of the interpreter application, several fundamental disaster response simulations were conducted with the author taking the role of hotel staff, and international students playing the roles of the international tourists [1]. It was clear from the simulations 
that it was also necessary to provide disaster information that encouraged international tourists to take action within the frameworks of their own cultures, disaster experiences, and legal systems. Overall, however, it was shown from the simulations that using an interpreter app for disaster response was effective for use in tourist facilities such as hotels.

Therefore, this study conducts a further disaster response simulation on international tourists using the interpreter app for a volcanic eruption disaster simulation at an amusement park with the actual employees. The purpose of this study is to verify the validity of disaster information provision methods and the ability to meet the three conditions: (1) what is happening, (2) what progress is being made, and (3) the actions they need to take: and were related to the tourists disaster experiences, natural predisposition, culture, customs and lifestyles, and legal system differences.

The disaster response simulation is conducted at the Fuji-Q Highland amusement park in Yamanashi Prefecture, Japan. Based on the simulation results, then, the important issues for the provision of disaster information to international tourists will be elucidated.

\section{DISASTER INFORMATION BY INTERNATIONAL VISITORS}

The Japanese archipelago has steep terrain and a fragile geology and despite its area being only $0.25 \%$ of the world, has about $7 \%$ of all active volcanoes, experiences about $20 \%$ of the world's magnitude 5 or greater earthquakes, and is subjected to one of more typhoons annually. However, due to climate change effects, the number of short-term heavy rain events has increased and the number of annual typhoon landings has doubled from 10 years ago to 4-6 times a year, with the size and scale of the typhoons expanding. Therefore, Japan suffers frequently from many natural events (hazards), such as earthquakes, tsunamis, heavy rain, heavy snowfall, typhoons, high waves and storm surges, landslides, slope failures, debris flows, and volcanic eruptions.

The Japanese government campaign to attract international tourists to Japan has significantly increased international tourism in Japan, with 31.88 million international tourists visiting in 2019, which was a significant increase on the 31.19 million visitors in 2018 and indicated the steady growth toward the 40 million target in 2020 . However, as the number of tourists grows, the chance of these tourists encountering a natural disaster also increases. However, it has been reported that international visitors find it difficult to gather information from Japanese $\mathrm{TV}$, radio or the internet on disaster situations or traffic conditions, especially during disasters [2]-[5]. Many international tourists are unaware of natural events such as earthquakes or typhoons as they have not experienced them before and many are very confused and distressed as they do not understand the local language and they do not know the names of the places and facilities [6].

It has been found that many international tourists seek information from the employees at their accommodation during disaster [2]-[5]. Fig. 1(a) shows the results of a questionnaire conducted by the Survey Research Center for foreign tourists on the evacuation and travel information sources used during the 2016 Kumamoto earthquake, and Fig. 1(b) shows the travel information sources during the 2018 Hokkaido Eastern Iburi earthquake, from which it can be seen that "accommodation employees" was ranked second in Fig. 1(a) and first in Fig. 1(b). In the hotel lobby, foreign tourists could ask the staff several times and get a satisfactory answer. However, in small- and medium-sized accommodation facilities, few employees have the ability to speak another language besides Japanese. Further, the tourists' home country websites ranked higher than either Japanese TV or radio, which indicated that international tourists were getting their information from their own media while in the affected areas. 


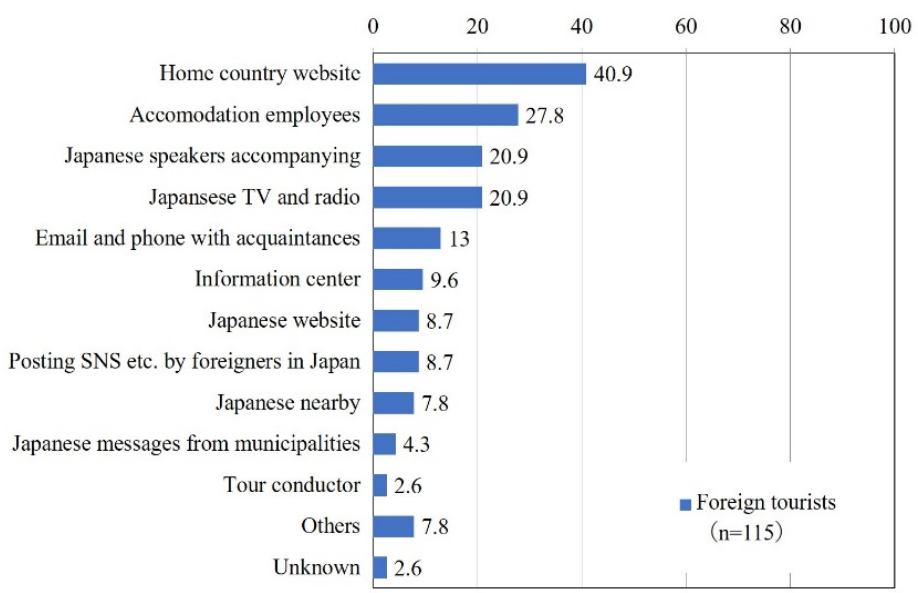

(a)

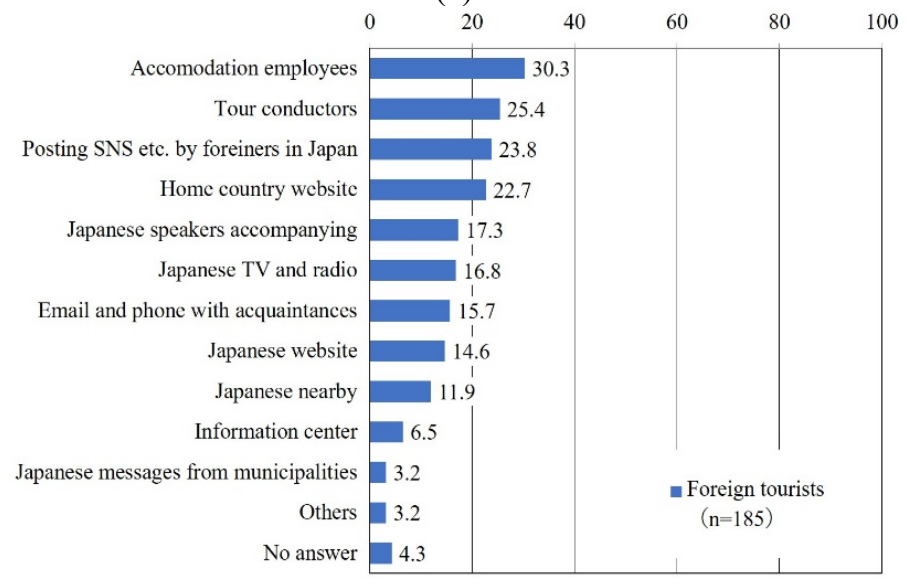

(b)

Figure 1: Necessary information for evacuation and travel during disasters. (a) The 2016 Kumamoto earthquake (Source: Survey Research Center, 2016 [2]); (b) The 2018 Hokkaido Eastern Iburi earthquake (Source: Survey Research Center [4]).

\section{MULTILINGUAL INTERPRETER APP}

Small- and medium-sized tourist facilities have few staff and even fewer who can speak another language besides Japanese, which makes it difficult for them to individually respond to inquiries by foreign tourists. As international visitors come from many countries, there is a need for information to be available in many different languages such as Chinese, Korean, English, Thai, Vietnamese, and Indonesian. Therefore, the author developed the idea of an interpreter app to provide information in many languages using a megaphone-type translator or a voice based small translator and a translation app that enables two-way conversations, which was consequently developed and implemented not only for normal guidance but also for disaster response in tourist facilities and for disaster management drills in municipalities, prefectures or temples and shrines with many tourists. Therefore, it is expected that this application could be used to provide tourist information during disasters in small- and 
medium-sized tourist facilities. However, when using these translators, it is necessary to select one language from which to translate, and in conversations using these translators or translation apps, two people have to talk face to face. Therefore, the translators and app do not allow tourist facility staff members to talk to multiple tourists in multiple languages.

For tourist facility employees to provide disaster information to multiple, multinational tourists simultaneously and to be able to answer tourist questions individually, an interpreter app that can translate from one-to-many and from Japanese-to-multiple languages is needed, which could also be used for tourist facility and guide commentaries for tourists during normal times. In this research, the "SmaLingual Pro" interpreter app, which was jointly developed by the author and Smart Culture Gateway Co., Ltd. and other companies, which has these functions, was selected (Fig. 2). This application is a paid service that provides simultaneous multilingual interpretation using a multilingual translation engine developed by the National Institute of Information and Communications Technology in Japan. The application can be downloaded from the Apple Store or Google Play, and with simple settings, it is possible to speak to multiple people in multiple languages with the same convenience as using a regular smartphone.

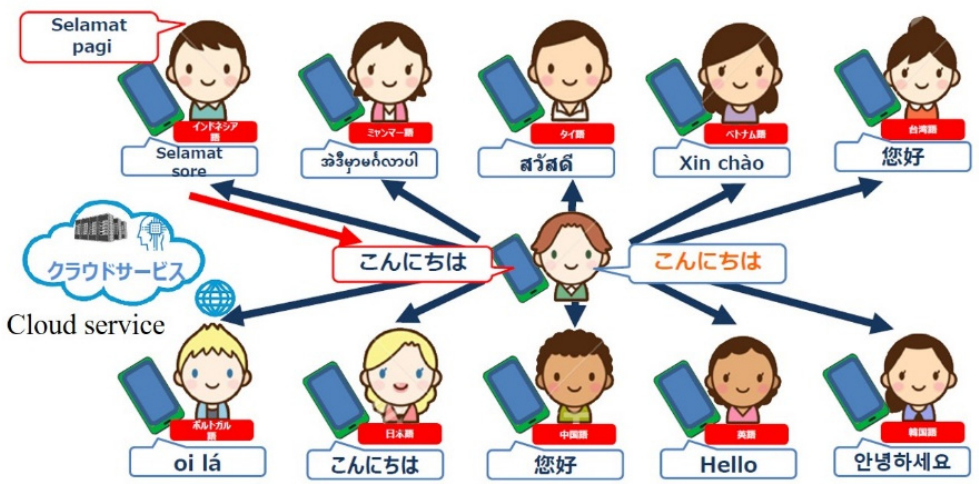

Figure 2: Schematic diagram to show features of the interpreter app. (Source: Smart Culture Gateway Co., Ltd. [7].)

\section{CURRENT STATUS OF VOLCANIC DISASTERS AND COUNTERMEASURES}

The volcanic island Whakaari/White Island in New Zealand's north-eastern Bay of Plenty region erupted on December 9, 2019. There were 47 people on the island at the time: twentyfour Australians, nine Americans, five New Zealanders, four Germans, two Chinese, two Britons, and one Malaysian. Twenty-one people were killed, including two who were missing and declared dead, and a further twenty-six suffered injuries, many of which were severe burns. Experts identified the event as a phreatic eruption, which launched rock and ash into the air.

The volcano had been showing signs of unrest for several weeks before the 2019 eruption. In October 2019, volcanic tremors and Sulphur dioxide gas were at their highest levels since 2016, indicating that an eruption was imminent, and on 18 November, the volcano was rated at a Volcanic Alert Level 2, indicating "moderate to heightened volcanic unrest". Directly after the eruption, the Volcanic Alert Level for the island was raised to a 4, but decreased by 16:30 on the same day to a level 3 [8]. 
A volcanologist claimed that the incident was "a disaster waiting to happen" and commented that the island was too dangerous to allow the daily tour group visits. However, even though there was the potential for eruption hazards to occur at Alert Level 2, the tours to the island were not restricted and tourists continued to regularly visit the island, primarily through White Island Tours.

In Japan, a similar phreatic eruption occurred at Mt. Ontake in September 2014, killing 58 people with a further five people missing. The Japan Meteorological Agency had observed an increase in volcanic earthquakes about two weeks before the phreatic explosion and called for caution; however, they did not raise the Volcanic Alert Level from 1, because the number of earthquakes decreased [9]. The Japan Meteorological Agency also did not give any further commentary information about the volcanic situation before raising the Alert Level. Only ten minutes before the eruption, volcanic tremors were observed due to magma ascending. Because the eruption occurred during the daytime during a holiday period, many climbers near the summit were affected.

The Japanese Meteorological Agency has an established system for setting and announcing volcanic eruption alert levels based on observation, after which the municipalities issue evacuation information based on the Alert Level, which is an index that categorizes the areas that needs alerting and the measures that need to be taken by disaster management agencies and residents based on five volcanic activity stages. The Volcanic Alert Levels in Japan, which are different from those in New Zealand [10], are applied to 41 volcanoes of the 111 active volcanoes in Japan, which are defined as those that have erupted within the last 10,000 years or those with active fumarolic activity.

Mt. Fuji is the largest active volcano in Japan, 70 craters of which, mainly at the foot of the mountain, have erupted in the past. Therefore, the Volcanic Alert Level can be raised from level 1 (active volcano) to level 3 (restriction to enter the mountain area) without going through level 2 (restriction to enter $1 \mathrm{~km}$ around a crater) only at Mt. Fuji. The volcanic disaster management system at Mt. Fuji requires different evacuation information to be issued in each different area based on crater location and the eruption status. Before the Meteorological Agency raises the Volcanic Alert Level from Level 1 to Level 3, it publishes volcanic observation information. However, to date, no commentary information has ever been released for Mt. Fuji since the Volcanic Alert Level announcement system was established, which means that none of the municipalities and tourist facilities at the foot of Mt. Fuji have not yet established systems to specifically respond when the volcanic observation information is announced.

\section{DISASTER RESPONSE SIMULATION IN JAPANESE AMUSEMENT PARK}

\subsection{Need for disaster response simulations}

Fundamental disaster response simulations had been previously conducted, in which the author played the role of the hotelier and international students played the roles of the tourists, from which it was confirmed that disaster information needed to be provided in plain language on: (1) what was happening, (2) the disaster progress, and (3) the subsequent actions to be taken [1]. In addition to these three conditions, the simulations also found that it was necessary to provide disaster information that encouraged international tourists to take action by accounting for their different cultures, disaster experiences, and legal systems. As the author was not familiar with hotel operations but is an expert in disaster management, it was necessary to verify the validity of the results from the fundamental disaster response simulations in an actual tourist facility. 
Therefore, the author planned a disaster response simulation using the interpreter app with international tourists and the Japanese employees at a Japanese amusement park. Fig. 3 illustrates the Japanese map and the location of the Fuji-Q Highland amusement park in Fujiyoshida City, Yamanashi Prefecture, a city famous for Mt. Fuji sightseeing located at the northern foot of Mt. Fuji. Approximately 2.3 million people annually visit the tourist facilities: the Fuji-Q Highland amusement park, hotels, pleasure boats, and ropeways: operated by the Fujikyukou Group. At the meeting with representatives of the Fujikyuko Co., Ltd., the time, place, and the two participating attractions staff were selected. The two staff did not receive any special training on the measures to be taken in the case of volcanic eruptions.

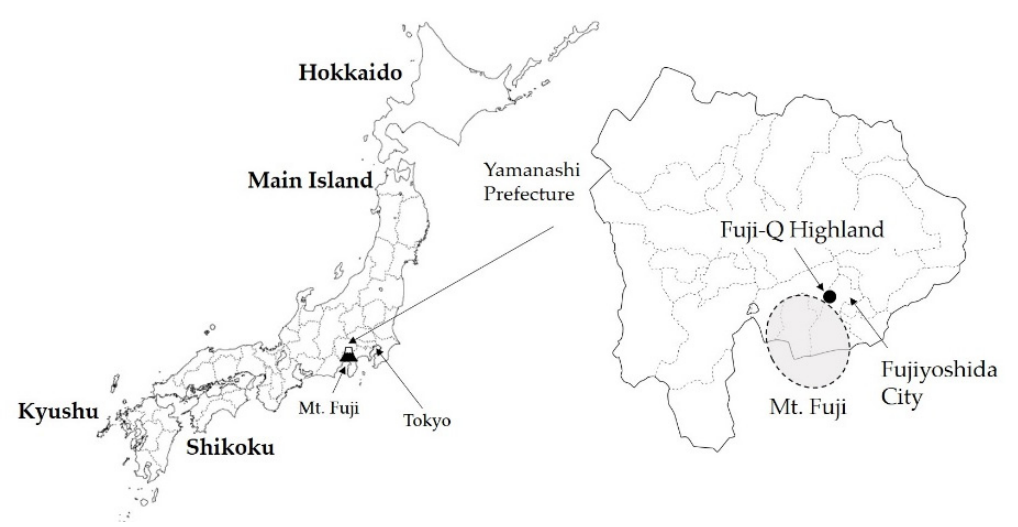

Figure 3: Japanese Archipelago and location of Fuji-Q Highland.

\subsection{Simulation scenario}

A simulation was conducted in which amusement park staff used the interpreter app to converse with international tourists about the volcanic situation. The simulation participants were the two staff from Fuji-Q Highland, two Chinese, and two Vietnamese. They were divided into two groups, one staff, one Chinese and one Vietnamese: with the two different groups conducting different simulation cases: direct translation of the announcement from the Japan Meteorological Agency and ingenious explanation in plain language. The simulation was based on an international tourist disaster response for a Volcanic Alert Level 3 announcement.

The simulation was conducted from 13:00 on December 20, 2019. One hour before the simulation, the Fuji-Q Highland staff participating in the simulation convened in a meeting room, where they downloaded the interpreter app onto their own smartphones and practiced how to use it. Then, the simulation preconditions shown in Table 1 were orally explained and also given in printed materials. The author also instructed each staff member about the simulation cases they were to participate in.

The simulation conditions were as follows. As shown in Table 1, two information commentaries on the situation at the volcano were released by the Japan Meteorological Agency two days before the simulation, and the staff members were informed that Fujiyoshida City had contacted Fuji-Q Highland with the details shown in Table 1. As the amusement park location was not included in the designated primary evacuation area, the 
Table 1: Messages transmitted to the amusement park staff.

\begin{tabular}{|l|l|}
\hline No. & \multicolumn{1}{|c|}{ Messages transmitted to the staff } \\
\hline 1 & $\begin{array}{l}\text { On December 18, the Japan Meteorological Agency released commentary on the } \\
\text { situation of the volcano, "We have observed volcanic earthquakes". }\end{array}$ \\
\hline 2 & $\begin{array}{l}\text { At 12:00 on December 19, the Japan Meteorological Agency announced } \\
\text { information on the situation of volcano, stating that "The number of volcanic } \\
\text { seismic observations is rapidly increasing" Immediately after the announcement } \\
\text { The Volcano Disaster Management Council of Mt. Fuji was held, and the local } \\
\text { governments participating in the council were alerted. As a result, the following } \\
\text { contact was also made from Fujiyoshida City to Fuji-Q Highland. No evacuation } \\
\text { information has yet been issued by the city. } \\
\text { "Mt. Fuji's volcanic activity is somewhat intense. The number of earthquakes has } \\
\text { increased rapidly beneath Mt. Fuji. Please be aware of future information". }\end{array}$ \\
\hline 3 & $\begin{array}{l}\text { The Japan Meteorological Agency raised the Volcanic Alert Level to 3 at 12:00 } \\
\text { on December 20 due to the observation of an inflation of the volcanic edifice at } \\
\text { the northern foot of Mt. Fuji. }\end{array}$ \\
\hline 4 & $\begin{array}{l}\text { As this announcement has been broadcast on TV news, to evacuate visitors from } \\
\text { the northern foot of Mt. Fuji, Fuji-Q Highland decided to close the park in the } \\
\text { afternoon, and decided to transport those guests without their own transportation } \\
\text { such as private cars or sightseeing buses to JR Otsuki Railway Station using Fuji- } \\
\text { Q's buses. }\end{array}$ \\
\hline 5 & $\begin{array}{l}\text { The amusement park decided to take special measures to guide. international } \\
\text { tourists to the third entrance and preferentially transport them by bus to JR Otsuki } \\
\text { Railway Station. }\end{array}$ \\
\hline 6 & $\begin{array}{l}\text { Fuji-Q Highland Resort Hotel decided to secure accommodation in Tokyo for } \\
\text { guests planning to stay on the 20th, and to take them to the accommodation by } \\
\text { bus. The hotel is currently making these arrangements, which are not } \\
\text { yet finalized. }\end{array}$ \\
\hline
\end{tabular}

amusement park was open as usual until the day before. It had been reported on TV that the Japan Meteorological Agency had raised the Volcanic Alert Level to 3 at 12:00; however, based on its own disaster management plan, Fuji-Q Highland decided to close the park in the afternoon and to evacuate the visitors to outside the north foot of Mt. Fuji. Because of prior consultation between the author and Fuji-Q Highland, the Fuji-Q Highland decided to take special measures for the international tourists to lead them to a parking lot away from the usual entrance and then preferentially transport them by bus. For those tourists who are also guests at the Fuji-Q Highland Resort Hotel, which is adjacent to the amusement park, Fuji-Q Highland decided to secure special accommodation in Tokyo and to move them to the accommodation by bus.

Of the two Chinese and two Vietnamese participating in the simulation, three were international students at University of Yamanashi and one was the brother of a Vietnamese international student. These four international participants had learned how to use the interpreter app in advance.

The simulation conditions were described as follows: (1) you came to Japan with your friends for sightseeing, not group travel; (2) as this is your first visit to Japan, you did not understand the conditions in Japan and could not speak Japanese; (3) you have no knowledge 
of volcanic eruptions, as you have only watched images on TV; (4) you have been staying at Fuji-Q Highland Resort Hotel since yesterday and came to Fuji-Q Highland to have fun. Yesterday, you got off the Fuji-Q Kanko limousine bus in front of the Fuji-Q Highland Resort Hotel; (5) you visited Arakura Fuji Asama Shrine this morning, and you are going to have fun at Fuji-Q Highland, stay at the hotel, and tomorrow afternoon, take a limousine bus from the hotel to Narita Airport and return home; (6) however, a staff member of Fuji-Q Highland explains using the interpreter app (SmaLingual Pro) that the park is to be closed; however, because you are not group tour visitors, your transportation is limited to public transport.

The simulation was conducted in front of the first or main entrance of the amusement park. For simulation convenience, the four international simulation participants needed to understand that this entrance was just a few minutes' walk from the Fuji-Q Highland Resort Hotel. Therefore, the author showed them the positional relationship using a map. As the disaster information to be given by the amusement park staff was different in the two cases: direct translation and ingenious explanation, the international participants were divided into two different groups and the conversation conducted using the interpreter app.

\subsection{Messages from the amusement park staff}

The Volcanic Alert Level 3 information from the Japan Meteorological Agency was conveyed in two different ways based on description No. 1 in Table 2: direct translation and ingenious explanation. Then in both cases, the international tourists were given messages Nos. 2 to 4 in Table 2 by the staff.

For the international tourists accommodated at the Fuji-Q Highland Resort Hotel, the author proposed to Fujikyu Corporation that these measures be incorporated into the simulation, which was accepted. In particular, for the ingenious explanation, preferential treatment was given to guests at the Fuji-Q Highland Resort Hotel, as shown in Table 3.

Table 2: Messages given by the staff to the international tourists.

\begin{tabular}{|l|l|l|}
\hline No. & \multicolumn{1}{|c|}{ Messages from staff of the amusement park } \\
\hline Case & \multicolumn{1}{|c|}{ Direct translation } & \multicolumn{1}{c|}{ Ingenious explanation } \\
\hline 1 & $\begin{array}{l}\text { Noticeable earthquakes have occurred } \\
\text { and an inflation of the volcanic edifice } \\
\text { is observed at the foot of Mt. Fuji. } \\
\text { The Japan Meteorological Agency } \\
\text { raised the Volcanic Alert Level up to } \\
\text { 3. Mountain climbing on Mt. Fuji has } \\
\text { been already prohibited. }\end{array}$ & $\begin{array}{l}\text { Several signs of the possibility of an } \\
\text { eruption were observed on Mt. Fuji, } \\
\text { and the Japan Meteorological Agency } \\
\text { announced that the possibility of an } \\
\text { eruption was high. } \\
\text { Mountain climbing on Mt. Fuji has } \\
\text { already been prohibited. } \\
\text { Nobody knows at this time whether Mt. } \\
\text { Fuji will erupt or not, and when, where } \\
\text { and how the eruption will occur. }\end{array}$ \\
\hline 2 & $\begin{array}{l}\text { For your safety, we have decided to close Fuji-Q Highland at this stage and ask } \\
\text { all of you to evacuate to outside the northern foot of Mt. Fuji. }\end{array}$ \\
\hline 3 & \begin{tabular}{l} 
Please follow the instructions from the staff. \\
\hline 4
\end{tabular} & $\begin{array}{l}\text { For foreign tourists who do not have a car or bus, please gather here. We will } \\
\text { take you to JR Otsuki Railway Station by bus. I will guide you to the parking lot } \\
\text { where buses will wait. } \\
\text { Do you have any questions? }\end{array}$ \\
\hline
\end{tabular}


Table 3: Preferential treatment for guests at the Fiji-Q Highland Resort Hotel.

\begin{tabular}{|l|l|}
\hline No. & Special message for tourists staying at the Fuji-Q Highland Resort Hotel \\
\hline 1 & $\begin{array}{l}\text { For the guests staying at the Fuji-Q Highland Resort Hotel today, we are } \\
\text { chartering a bus, which is in front of the hotel. }\end{array}$ \\
\hline 2 & $\begin{array}{l}\text { The hotel is secure. Please be assured that the bus will leave after you have } \\
\text { prepared your luggage. }\end{array}$ \\
\hline 3 & The Fuji-Q Highland Resort Hotel will also arrange a hotel in Tokyo. \\
\hline 4 & The arranged bus will take you to the hotel where you will stay today. \\
\hline 5 & $\begin{array}{l}\text { We will not refund today's accommodation fee, but we will pay for your hotel } \\
\text { accommodation in Tokyo. }\end{array}$ \\
\hline 6 & The hotel staff will be happy to assist you. \\
\hline
\end{tabular}

\subsection{Results of the simulation}

Fig. 4 shows photographs of the simulation. Fig. 4(a) shows the staff member at Fuji-Q Highland transmitting information using the smartphone in the direct translation case, and Fig. 4(b) shows the case of ingenious explanation, in which the staff member calls the two tourists staying at the nearby Fuji-Q Highland Resort Hotel and explains the evacuation procedure by bus from the hotel.

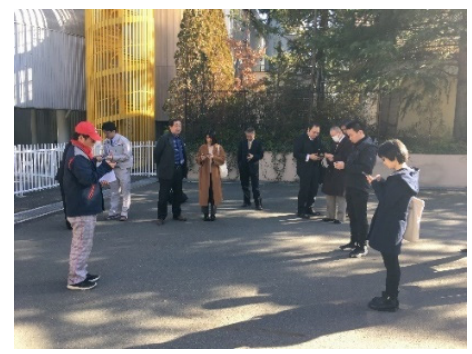

(a)

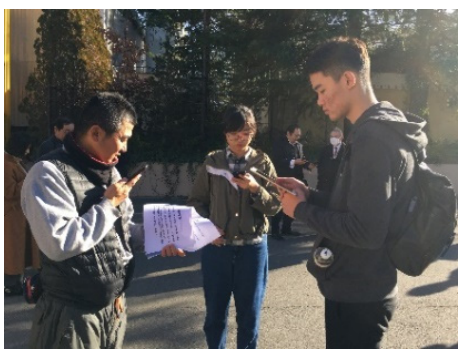

(b)

Figure 4: Photograph of disaster response experiment in the amusement park. (a) Case of direct translation; (b) Case of ingenious explanation.

Table 4 summarizes the questions and remarks from the tourists and the responses of the staff at the amusement park after the staff transmitted the messages shown in Table 2 for the information communicated through direct translation. In the speaker's column in Table 4, S1 indicates the amusement park staff, $\mathrm{C} 1$ indicates a Chinese tourist, V1 indicates the Vietnamese tourist, A was a question about what was happening, B was a question of how it would evolve, $\mathrm{C}$ was a question of what actions to take, $\mathrm{D}$ was a query about the jargon, $\mathrm{E}$ was a request from a tourist at the hotel, and $\mathrm{F}$ was a complaint about the hotel by a tourist.

Table 5 summarizes the questions and remarks from the international tourists and the staff responses after the staff transmitted the message shown in Table 2 for the case communicated by ingenious explanation. In the speaker's column in Table 5, S2 indicates the amusement park staff, C2 indicates a Chinese tourist, and V2 indicates a Vietnamese tourist.

The Chinese tourist said she wanted to return to the Fuji-Q Highland Resort Hotel to pick up her luggage, but the intention was not well communicated to the staff at the amusement 
Table 4: Conversations between tourists and the staff in the direct translation case.

\begin{tabular}{|l|l|c|}
\hline Speaker & Content of conversation & Classification \\
\hline C1 & Is it dangerous when the volume of the mountain increases? & D \\
\hline V1 & I stay at a nearby hotel. There is no car to return. & C \\
\hline V1 & Is the volcano erupting from now? & B \\
\hline C1 & What is the volcanic eruption situation? & A \\
\hline V1 & Please tell us about the current dangerous situation. & \\
\hline S1 & I do not know. & C \\
\hline C1 & We have to travel by bus don't we, because it is dangerous? & C \\
\hline S1 & Yes, please move right away. & \\
\hline C1 & Where are we going now? & C \\
\hline S2 & $\begin{array}{l}\text { We are going to the parking area where the buses for evacuation } \\
\text { park. }\end{array}$ & C \\
\hline V1 & Is it dangerous here? Do I have to get on the bus? & C \\
\hline C1 & Is it far from here? & B \\
\hline S1 & It will take about 5 minutes on foot. & C \\
\hline V1 & What do we do after getting on the bus? Where does the bus go? & F \\
\hline C1 & Is it safe to return to the hotel? & \\
\hline V1 & Can I stay here for sightseeing? & $\begin{array}{l}\text { Why is Fuji-Q Highland unsafe while there is a safe place only 5 } \\
\text { minutes by walk? }\end{array}$ \\
\hline C1 & I will guide you. Please listen. & \\
\hline S1 &
\end{tabular}

Table 5: Conversations between tourists and the staff in the ingenious explanation case.

\begin{tabular}{|l|l|c|}
\hline Speaker & Content of conversation & Classification \\
\hline C2 & I need to return to the hotel to get my luggage. & C \\
\hline C2 & I am going back to the hotel. & C \\
\hline V2 & Please tell me the directions to the bus stop. & \\
\hline S2 & I will guide you as soon as all guests have gathered. & C \\
\hline V2 & I am going back to the hotel. & C \\
\hline S2 & Which hotel are you staying at? & \\
\hline V2 & I am going to the hotel in Tokyo. & \\
\hline S2 & $\begin{array}{l}\text { We will take you to JR Otsuki Railway Station by bus to return to } \\
\text { your hotel in Tokyo. }\end{array}$ & \\
\hline V2 & I understand. & \\
\hline S2 & Thank you very much. Please wait a little more. & \\
\hline V2 & I understand. & \\
\hline S2 & $\begin{array}{l}\text { Are there any guests staying at Fuji-Q Highland Resort Hotel? } \\
\text { Please raise your hand if you are staying at Fuji-Q Highland Resort } \\
\text { Hotel. }\end{array}$ & \\
\hline & C2 and V2 raised their hands & \\
\hline S2 & The employee verbally explained what was described in Table 5. & \\
\hline S2 & Do you understand? & \\
\hline V2 & Yes, I do. & \\
\hline
\end{tabular}


park, and the Vietnamese tourist indicated his willingness to follow the staff's proposal to be evacuated and leave his luggage at the hotel. He could take the bus from the hotel where he was staying, while the staff member sent a message with the content shown in Table 3.

As described above, even though only five dialogues classified as $\mathrm{C}$ regarding the actions to be taken by the tourists were mentioned, it was found that the description of the volcano situation by the amusement park staff was understood by the two tourists. If the hotel prepares in advance to respond to guests at the Fuji-Q Highland Resort Hotel, as shown in Tables 2 and 3 , the responses can be implemented more smoothly.

Fig. 5 shows a comparison of the results between the two cases in which the questions were classified into six types in the horizontal axis, with the vertical axis indicating the number of questions. In this figure, the question and remark contents from the tourists shown on the horizontal axis were classified into six types: what is happening now, how it will progress, what actions should be taken, easy-to-understand expressions, request for support, and complaint or dissatisfaction with staff responses. As shown in the figure, when the information announced by the Japan Meteorological Agency case was transmitted to the international tourists using an ingenious explanation, the number of questions was reduced to five from the thirteen for the direct translation case, and the question content was focused on the actions to be taken. Therefore, it was shown that it was more effective to explain the messages to the tourists using ingenious explanations.

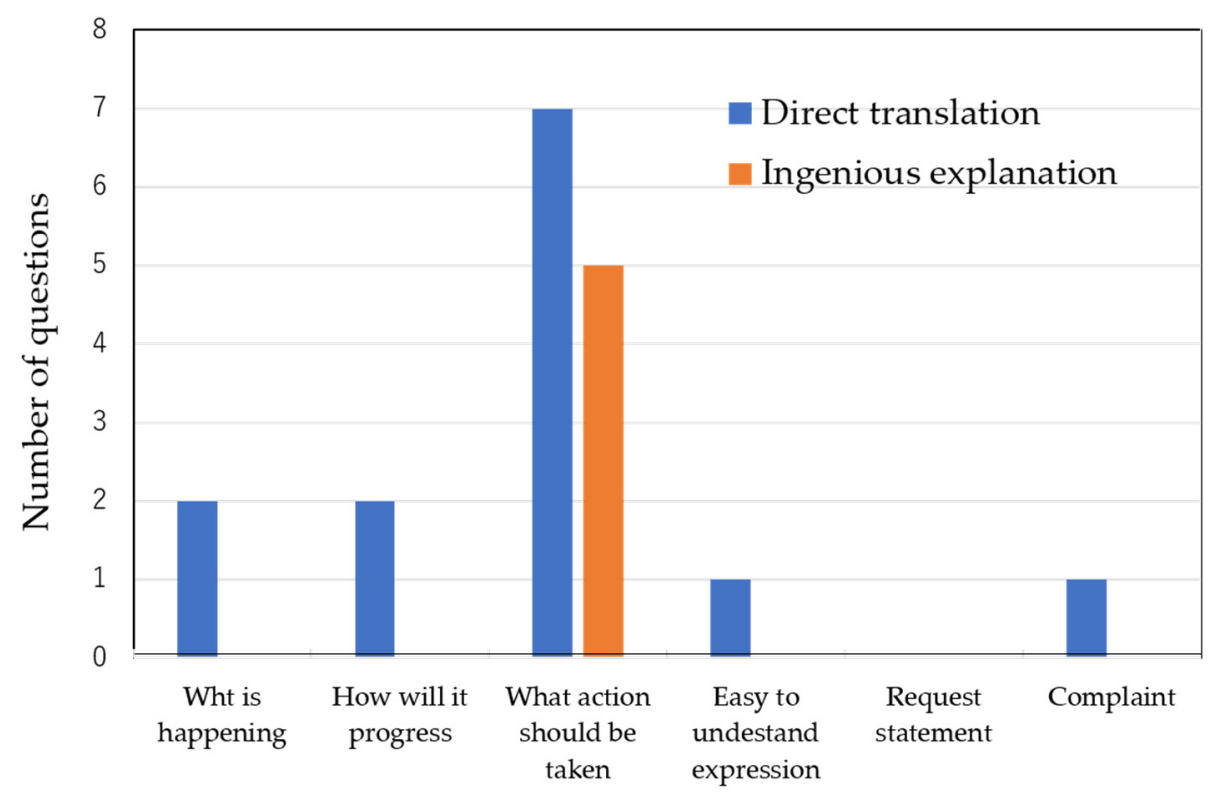

Figure 5: Comparison the results of experiment between two cases.

Despite the same evacuation guidance being given by the staff after the volcano information, there were significant differences found between the two cases. The reason for these differences was because the international tourists did not understand the technical term translations, such as "the occurrence of a felt earthquake", "inflation of the volcanic edifice", and "Volcanic Alert Level 3", as the regions from which the four international tourists were 
from had no natural predisposition to volcanic eruptions and therefore, they had not received disaster education on volcanic eruptions. Neither China nor Vietnam has a system for volcanic alert levels, and Vietnam has no volcanoes; therefore, the legal systems for evacuation vary from country to country. The amusement park staff who participated in the simulation had also had no prior education or training on volcanoes and volcanic eruption disaster responses, and it had been confirmed before the simulation that they also did not know the meaning of the specific jargon used by the Japan Meteorological Agency.

\subsection{Discussions}

Tourist facilities that do not have any expertise on volcanoes often do not know what is happening and the progress of the disaster. Therefore, municipalities need to access information immediately from specialized agencies such as the Japan Meteorological Agency and transmit it to tourist facilities in plain easy-to-understand language. The simulation in this paper verified that it is necessary to provide information to international tourists that satisfy the above three conditions.

When a Volcanic Alert Level 3 is issued, municipalities such as Fujiyoshida City are required to issue evacuation preparation information that calls for evacuation assistance for people who need evacuation assistance, but they are not legally required to issue evacuation advisory information to healthy populations. As tourists are people who need assistance during such evacuations, the author proposed closing the park and evacuating all guests outside the northern foot of Mt. Fuji. Needless to say, tourism crisis management can minimize the damage caused by disasters and allow for the resumption of the original tourism business as soon as possible after the end of the disaster [11], [12]; therefore, this simulation suggested that there was a need to have readily available tourism crisis management plans.

The amusement park staff who participated in the simulation had not had any prior education or training on volcanoes or volcanic eruption disaster response, and therefore had no knowledge of the meaning of jargonized language issued by the Japan Meteorological Agency. The one-to-many, Japanese-to-multilingual interpreter app was proven to be a powerful tool for tourist facilities in the event of a disaster. However, to make effective use of this app in an actual disaster, simulations/drills such as the one described in this paper should be conducted and disaster response manuals prepared and verified through training. Regular disaster response and manual verification simulations/drills using the interpretation application could be powerful preparation for tourist facility staff and management.

Since the simulation was conducted in front of the main entrance of Fuji-Q Highland, the volume of audio guidance broadcast from the speakers was large, and the noise when a large roller coaster in the park passed was also loud. When there were these loud sound sources around, participants had to stop talking on the smartphone. However, compared to about a few years ago, in recent years the voice recognition technology of smartphone microphones and software has been significantly advanced, and it has been confirmed that unless the wind is strong enough to be able to talk, the sound of the wind will not be a big obstacle to voice recognition.

In noisy situations, participants could pause the conversation and wait for it to be quiet. However, the accent, poor pronunciation, and habits of speakers have troubled the voice recognition function of smartphones, and as a result, have sometimes resulted in mistranslation. The staff of Fuji-Q Highland who participated in the simulation spoke not with the standard language, but with accents and speaking styles unique to the northern foot of Mt. Fuji, which seemed to reduce the accuracy of translation. Despite the hope that the 
translation engine will be improved, employees of hospitality industry need to be trained to speak slowly according to the disaster response manual with the correct translatable accents.

In order for international tourists to take appropriate evacuation actions according to the information, it is important for tourism and hospitality industry employees, first of all, to remain international tourists calm. Even if they send the same message, it should be received differently depending on the nationality, cultural, religious background and so on. In the simulation, the emphasis was placed on properly communicating the unknown natural threat of volcanic eruptions to international visitors, leading them to evacuate in the area strange to them. Furthermore, it is necessary to devise ways to provide information to calm such international tourists, and this will be a future issue to be studied.

Both of the two Chinese who participated in the simulation spoke Mandarin, the standard language. Therefore, a relatively appropriate translation was performed by the interpreter app. However, in the fundamental experiments conducted previously involving 11 Chinese students [1], there were many cases in which correct translation was not performed due to dialects and dullness. Therefore, the experiment involved only five students who could speak relatively standard languages. On the contrary, one of the two Vietnamese who participated in the simulation spoke the standard language, but the other one had an accent in the language, so the app was often mistranslated. Thus, the translation engine still needs improvement and expansion. Furthermore, proper nouns representing the names of facilities such as Fuji-Q Highland and Fuji-Q Highland Resort Hotel and place names such as Otsuki need to be registered in a dictionary in advance.

\section{CONCLUSIONS}

This paper used an innovative interpreter app in a disaster response simulation targeting volcanic eruption disasters for international tourists at an amusement park with the participation of actual staff, from which the following conclusions were derived:

1) The provision of disaster information to international tourists using ingenious explanations about (1) what is happening, (2) how it is progressing, and (3) the actions to be taken were more effective. Only five questions focused on what actions should be taken were asked by the international tourists in ingenious explanation case compared to the thirteen questions asked when the Japan Meteorological information was directly translated.

2) Neither China nor Vietnam has a system for volcanic alert levels, and Vietnam has no volcanoes; therefore, it is necessary to devise ways to provide information taking the legal systems, disaster experiences, natural predispositions in other countries. It is also necessary to remain international tourists calm during disasters in order to take appropriate evacuation actions according to the information. The way of reacting is different according to nationality, cultural background. Thus, how to calm international tourists is a future issue to be studied.

3) It is imperative that municipalities obtain information from specialized disaster management organizations such as the Japan Meteorological Agency as early as possible and transmit this information to tourist facilities using ingenious and plain language.

4) The simulation suggested that there was a need for a comprehensive tourism crisis management plan.

5) Simulations/drills at tourism facilities using the interpretation application could prepare staff for disasters and successfully verify the validity of disaster response manuals. 


\section{REFERENCES}

[1] Suzuki, T. \& Yang, J., Experimental study on disaster response to foreign tourists using the interpreter software. Proceedings of the 17th International Conference on Earthquake Engineering, Sendai, Japan, 2020.

[2] Survey Research Center, Survey on evacuation behavior of foreign tourists visiting Japan during the Kumamoto earthquake 2016. www.surece.co.jp/research/1782/. Accessed on: 14 Feb. 2020.

[3] Survey Research Center, Survey on evacuation behavior of foreign tourists visiting Japan during the Osaka Northern Earthquake. www.surece.co.jp/research/2441/. Accessed on: 14 Feb. 2020.

[4] Survey Research Center, Survey on evacuation behavior of foreign tourists visiting Japan during the 2018 Hokkaido Northern Iburi earthquake. www.surece.co.jp/ research2491/. Accessed on: 14 Feb. 2020.

[5] Survey Research Center, Survey on evacuation behavior of foreign tourists visiting Japan during the 2019 off Yamagata Prefecture earthquake.

[6] Vargas-Sanchez, A., Crisis situation in tourist destinations: how can they be managed?. Enlightening Tourism. A Pathmaking Journal, 8(4), pp. 47-69, 2018.

www.surece.co.jp/research2968/. Accessed on: 14 Feb. 2020.

[7] Smart Culture Gateway Co, Ltd., Brochure for SmaLingual Pro 2019.

[8] Wikipedia, Whakaari/White Island eruption 2019. https://en.wikipedia.org/wiki/ 2019_Whakaari_/White_Island_eruption. Accessed on: 14 Feb. 2021.

[9] Suzuki, T., Wis $\bar{d}$ - Tem, Techniques and Mechanisms for Protecting Lives from Catastrophes, ITSC Ltd.: Shizuoka, 2014.

[10] Potter, S.H., Jolly, G.E., Neall, V.E., Johnston, D.M. \& Scott, B.J., Communicating the status of volcanic activity: revising New Zealand's volcanic alert level system. Journal of Applied Volcanology, 3(13), pp. 1-16, 2014.

[11] Richie, B.W., Crisis and Disaster Management for Tourism (Aspects of Tourism), Channel View Books: Bristol, 2009.

[12] Barent, N.M., The Need to be prepared: Disaster management in the hospitality industry. Journal of Business and Hotel Management, 1(2), 2012.

DOI: $10.4172 / 2324-9129.1000101$. 